\title{
The 19-bp deletion polymorphism of dihydrofolate reductase (DHFR) and nonsyndromic cleft lip with or without cleft palate: evidence for a protective role
}

\author{
Firoozeh RAFIGHDOOST ${ }^{1}$, Amir RAFIGHDOOST ${ }^{2}$, Houshang RAFIGHDOOST ${ }^{3}$, Mohammad-Ayoob RIGI-LADEZ ${ }^{1}$, \\ Mohammad HASHEMI ${ }^{4}$, Ebrahim ESKANDARI-NASAB ${ }^{4}$
}

1- School of Dentistry, Zahedan University of Medical Sciences, Zahedan, Iran.
2- School of Medicine, Mashhad University of Medical Sciences, Mashhad, Iran.
3- Department of Anatomy, School of Medicine, Zahedan University of Medical Sciences, Zahedan, Iran.
4- Department of Clinical Biochemistry, School of Medicine, Zahedan University of Medical Sciences, Zahedan, Iran.

Corresponding address: Ebrahim Eskandari-Nasab - Department of Clinical Biochemistry, School of Medicine, Zahedan University of Medical Sciences Zahedan - Iran - P.O.BOX:+9861615881 - Phone: +98-9136326859 - Fax: +98-5413229792

e-mail:eenasab@yahoo.com / eenasab@sadi.ut.ac.ir

Submitted: December 12, 2014 - Modification: April 19, 2015 - Accepted: April 27, 2015

ABSTRACT

$\mathrm{O}$ bjective: Nonsyndromic cleft lip with or without cleft palate (NS-CL/P) are among the most common congenital birth defects worldwide. Several lines of evidence point to the involvement of folate, as well as folate metabolizing enzymes in risk reduction of orofacial clefts. Dihydrofolate reductase (DHFR) enzyme participates in the metabolic cycle of folate and has a crucial role in DNA synthesis, a fundamental feature of gestation and development. A functional polymorphic 19-bp deletion within intron-1 of DHFR has been associated with the risk of common congenital malformations. The present study aimed to evaluate the possible association between DHFR 19-bp deletion polymorphism and susceptibility to NS-CL/P in an Iranian population. Material and Methods: The current study recruited $100 \mathrm{NS}-\mathrm{CL} / \mathrm{P}$ patients and 100 healthy controls. DHFR 19-bp deletion was determined using an allele specific-PCR method. Results: We observed the DHFR 19-bp homozygous deletion genotype (D/D) vs. homozygous wild genotype (WW) was more frequent in controls than in NS-CL/P patients $(25 \%$ vs. $13 \%)$, being associated with a reduced risk of NS-CL/P in both codominant $(\mathrm{OR}=0.33, \mathrm{P}=0.027)$ and recessive $(\mathrm{OR}=0.45$, $\mathrm{P}=0.046$ ) tested inheritance models. We also stratified the cleft patients and reanalyzed the data. The association trend for $\mathrm{CL}+\mathrm{CL} / \mathrm{P}$ group compared to the controls revealed that the $\mathrm{DD}$ genotype in both codominant $(\mathrm{OR}=0.30, \mathrm{P}=0.032)$ and recessive models $(\mathrm{OR}=0.35$, $\mathrm{P}=0.031$ ) was associated with a reduced risk of $C L+C L / P$. Conclusions: Our results for the first time suggested the DHFR 19-bp D/D genotype may confer a reduced risk of NS-CL/P and might act as a protective factor against NS-CL/P in the Iranian subjects.

Keywords: Dihydrofolate reductase (DHFR). Nonsyndromic cleft lip with or without cleft palate (NS-CL/P). Ins/Del polymorphism.

\section{INTRODUCTION}

Orofacial clefts (OFC), including cleft lip with or without cleft palate (CL/P) and cleft palate only or isolated cleft palate (CP), are among the most frequent inborn birth defects worldwide ${ }^{20}$. According to their association with special malformative patterns or their incidence as isolated defects,
$\mathrm{CL} / \mathrm{P}$ can be classified into Syndromic and Nonsyndromic (NS-CL/P), respectively. Most CL/P cases (approximately 70\%) are nonsyndromic, although strong genetic factors contribute in both forms. Syndromic forms are typically caused by chromosomal aberrations or monogenic diseases, whereas, NS-CL/P forms result from the interaction between genetic and environmental factors. NS-CL/P 
patients frequently suffer from major complications such as difficulties concerning feeding, speech, hearing, and psychologic maturation ${ }^{19,21}$.

Nonsyndromic or isolated (without other associated abnormalities) $\mathrm{CL} / \mathrm{P}$ is a common congenitally developmental disorder affecting 1:700 births worldwide, although this rate is different in various ethnic groups and geographic regions ${ }^{19,21}$. Generally, Asian populations have a higher birth occurrence of clefting (1/500 births), Caucasians are intermediate $(1 / 1,000$ births), and African populations have the lowest $(1 / 2,500$ births). It has been reported that the incidence of $\mathrm{CL}$ and $\mathrm{CP}$ in Iran is approximately $1 / 1,000$ lower than that in other countries. Clefting is caused by a coordinated sequence of events that involve the growth of several independently-derived facial primordia. Genetic and environmental factors, and their interactions, may affect these events and contribute to NS-CL/P pathogenesis ${ }^{20}$.

The development of craniofacial structures is the product of social environmental, and nutritional factors such as tobacco smoke, alcohol consumption, and maternal folic acid deficiency due to exposure to folic acid antagonists - such as anticonvulsants ${ }^{26}$ - appear to play a role in the development of OFC during pregnancy ${ }^{8}$. Folic acid is a water soluble B-vitamin that plays a crucial role in embryonic development because it is essential for DNA stability maintenance, being involved in DNA synthesis, repair, and methylation ${ }^{4,22}$. Alterations in genes responsible for each step of the folate pathway has been shown to cause aberrations in organogenesis that result in congenital malformations such as neural tube defects (NTDs) ${ }^{6}$ or OFC ${ }^{4}$. Several lines of evidence have confirmed there is a reduced risk of OFC and NTDs when mothers used either folic acid-containing supplements or dietary folate during the periconceptional period. For example, a meta-analysis of 11 case-control studies and four prospective studies supported the hypothesis that taking folic acid-containing supplements during pregnancy decreases the risk of NS-CL/P1.

The metabolic cycle of folate is complex, with multiple genes participating in the transformation of folate into various compounds ${ }^{8}$. One of these genes is dihydrofolate reductase (DHFR), known as a strong candidate for a teratogenic locus which synthesizes the DHFR enzyme. All of the folate from vitamin supplements and food fortification is folic acid, a form of folate that is unreduced and requires the action of DHFR before it can participate in cellular reactions. DHFR converts the dihydrofolate (DHF) into tetrahydrofolate (THF) forms that can contribute to folate/homocysteine metabolism, and subsequent DNA synthesis, a fundamental feature in fetal development and organogenesis.

Several gene polymorphisms affect folate metabolism and are associated with reduced folate absorption and consequently increased folate needs. In the absence of a folate-sufficient diet, these gene alterations are associated with increased risk of NTDs and congenital defects in the offspring ${ }^{4}$.

The DHFR gene is located at chromosome 5q11.2-13.2 and is expressed in three mRNA isoforms with alternatively spliced $3^{\prime} U T R$ ends. The changes in DHFR expression or activity can be partly due to the functional polymorphisms in the DHFR gene, thereby influencing a risk of folate-dependent diseases $^{17}$. A polymorphic 19-bp deletion within intron-1 of DHFR has been described; however, its biological consequence has been inconsistent. Accordingly, the DHFR 19-bp deletion polymorphism has been associated with a reduced or increased risk of some congenital malformations. For instance, the DHFR 19-bp deletion (D)/D genotype in mothers has been associated with an increased risk of having a baby born with spina bifida $(\mathrm{SB})^{13}$; whereas other studies have suggested the DHFR 19-bp D/D genotype is protective against having a baby born with $\mathrm{SB}^{18}$ or NTD ${ }^{9,14}$, verifying the inconsistency among different studies.

With respect to the crucial role of folic acid in embryonic development, any genetic variations in the DHFR gene leading to impaired folate metabolism could possibly contribute to predisposition to NS$\mathrm{CL} / \mathrm{P}$. Therefore, the present study aimed to evaluate the possible association between functional 19-bp deletion polymorphism within intron-1 of DHFR and susceptibility to NS-CL/P in an Iranian population. To the best of our knowledge, this is the first study examining the possible impact of DHFR 19-bp deletion gene variation on NS-CL/P.

\section{MATERIAL AND METHODS}

In the current case-control retrospective study, a total of 200 subjects - including 100 $\mathrm{CL} / \mathrm{P}$ patients (61 male and 39 female) with an average age of 12.12 years (Range: $1-54 \mathrm{y}$ ) and 100 normal subjects (61 male and 39 female) with an average age of 12.03 years (Range: $1-51$ y) - were involved as previously described by this research team ${ }^{19}$. All samples were collected from Zahedan, a South-east Iranian population. The control samples were unaffected, unrelated individuals without a family history of clefting, collected as randomly selected, population-based controls from Zahedan. The diagnosis was made at the time of birth by physical examination. All patients were diagnosed independently and were screened to exclude cleft-associated syndromes such as DiGeorge syndrome, Stickler syndrome, Nager syndrome, and Van der Woude syndrome by the multidisciplinary team of specialists of each center. There was no significant difference between 
the groups regarding sex and age $(P>0.05)$. All participants were unrelated to each other.

The local Ethics Committee of the Zahedan University of Medical Sciences approved the project, and written informed consent was taken from all participants (or their parents). Blood samples from all patients and healthy controls were collected in EDTA containing tubes and stored at $-20^{\circ} \mathrm{C}$ until DNA extraction. Genomic DNA was extracted from the peripheral blood leukocytes by the "salting-out" method as described previously. The quality of the isolated DNA was checked by electrophoresis on $1 \%$ agarose gel, quantitated spectrophotometrically, and stored at $-20^{\circ} \mathrm{C}$ until further use.

Genotyping of the 19-bp deletion of DHFR was performed using the allele specific-PCR (ASPCR) as described previously by Gemmati, et al. ${ }^{11}$ (2009). In the AS-PCR, two different allele-specific forward primers (F1 and F2) for the non-deleted and deleted polymorphic alleles, respectively, and one common reverse primer $(R)$ were applied. To verify the accuracy of the method, random samples were genotyped by a bi-directional PCR allelespecific amplification (bi-PASA) PCR as established previously by Eskandari-Nasab, et al. ${ }^{8}$ (2012) and Rafighdoost, et al. ${ }^{27}$ (2013). The bi-PASA included two outer primers (FO and RO) and two inner allele-specific primers, FI (Insertion allele) and RI (Deletion allele), all in one-tube PCR reaction. PCR was performed using commercially available Prime Taq premix (Genetbio, Chungcheongnam, South Korea) according to the manufacturer's recommended protocol. Briefly, $1 \mu \mathrm{L}$ template DNA $(\sim 100 \mathrm{ng} / \mu \mathrm{L}), 0.7 \mu \mathrm{L}$ of each primer $(10 \mathrm{pmol} / \mathrm{mL})$, $10 \mu \mathrm{L}$ Prime Taq premix, and $7 \mu \mathrm{L}$ DNase-free water were added to each PCR tube in a final volume of $20 \mu \mathrm{L}$. Amplification was performed with an initial denaturation step at $95^{\circ} \mathrm{C}$ for $5 \mathrm{~min}$, followed by 30 cycles at $95^{\circ} \mathrm{C}$ for $30 \mathrm{~s}, 60^{\circ} \mathrm{C}$ for $30 \mathrm{~s}$, and $72^{\circ} \mathrm{C}$ for $25 \mathrm{~s}$ with a final extension at $72^{\circ} \mathrm{C}$ for $10 \mathrm{~min}$. Each reaction was verified on a $2 \%$ agarose gel. The AS-PCR results were $100 \%$ concordant with the findings of bi-PASA. All primers sequence and amplicons size are presented in Figure 1.

\section{Statistical analysis}

The statistical analyses of the data were performed by the SPSS 18.0 software (SPSS Inc, Chicago IL, USA). The associations between alleles or genotypes and NS-CL/P were assessed by computing the odds ratio (OR) and $95 \%$ confidence intervals (95\% CI) from logistic regression analyses. P-values below 0.05 were determined statistically significant. Based on our results, sample power was analyzed for DHFR polymorphism by comparison of each genotype with the accumulation of other genotypes by utilizing STATA 10 software.

\section{RESULTS}

Of a total of 100 patients, 43 were $C L, 26$ were CLP, and 31 were cleft palate only $(C P)$. The distribution of genotype and allele frequencies of $D H F R$ 19-bp deletion polymorphism is presented in Table 1 . Our results revealed a statistically significant association between DHFR 19-bp deletion polymorphism and susceptibility to NS-CL/P in both the codominant and recessive tested inheritance models. In the codominant model, the DHFR 19bp homozygous deletion genotype (D/D), with an increased frequency in controls compared to NS$\mathrm{CL} / \mathrm{P}$ patients ( $25 \%$ vs. $13 \%)$, was associated with a reduced risk of NS-CL/P (D/D vs. W/W genotype; $O R=0.33,95 \% C I=0.32-0.88 ; P=0.027)$. Similarly, in the recessive model, the DHFR 19-bp D/D genotype was associated with susceptibility to NS-CL/P and may confer a decreased risk against NS-CL/P (D/D vs. W/W+W/D genotype; OR=0.45, 95\% CI=0.20-0.99; $\mathrm{P}=0.046)$.

On the other hand, at the allelic level, the DHFR 19-bp deletion (D) allele was more prevalent in the control group compared to the NS-CL/P patients (43\% vs. $33 \%)$, although it was not significantly associated with the risk of NS-CL/P (D allele vs. W allele; $O R=0.68,95 \% \mathrm{CI}=0.45-1.03, \mathrm{P}=0.072$ ).

Table 2 shows the association of DHFR 19-bp

\begin{tabular}{|c|c|c|}
\hline Primers & Sequence $\mathbf{~ ( 5}^{\prime}$ to $\mathbf{3}^{\prime}$ ) & Amplicon size \\
\hline Genotyping Method & Bi-PASA PCR & 357 bp \\
\hline DHFR-FO & CTGTCATGGTTGGTTCGCTAAAC & $159 \mathrm{bp}$ \\
\hline DHFR-RO & TGGGTAGGGGTGGGTGTTTTC & $239 \mathrm{bp}$ \\
\hline DHFR-FI (Del allele) & CCACGGTCGGGGTACCTGGG & $113 \mathrm{bp}$ and \\
\hline DHFR-RI (Ins allele) & GAGTCGGCCACCCCGACCGT & $92 \mathrm{bp}$ \\
\hline Genotyping Method & Allele-Specific PCR & \\
\hline DHFR-F1 & TCGGGGTACCTGGG & \\
\hline DHFR-F2 & ACGGTCGGGGTGGCCGACTC & \\
\hline DHFR-R & AAAAGGGGATCCAGTCG & \\
\hline
\end{tabular}

Figure 1- Primers sequence for detection of DHFR 19-bp deletion polymorphism 
Table 1- Genotype and allele frequencies of DHFR 19-bp deletion polymorphism between patients with nonsyndromic cleft lip and/or cleft palate (NS-CL/P) and control subjects

\begin{tabular}{lccccc}
\hline \multicolumn{1}{c}{ Genotypes } & NS-CL/P Patients $\mathbf{n}(\%)$ & Controls $\mathbf{n}(\%)$ & OR (95\% $\mathbf{C l})$ & P-value & Study Power $\%$ \\
\hline DHFR, 19-bp deletion polymorphism & & & & \\
Codominant & & & & \\
W/W & $19(19)$ & $12(12)$ & Reference & - & 22 \\
W/D & $68(68)$ & $63(63)$ & $0.68(0.31-1.52)$ & 0.348 & 9 \\
D/D & $13(13)$ & $25(25)$ & $0.33(0.32-0.88)$ & 0.027 & 51 \\
Dominant & & & & \\
W/W & $19(19)$ & $12(12)$ & Reference & - & 22 \\
W/D+D/D & $81(81)$ & $88(88)$ & $0.58(0.25-1.36)$ & 0.241 & 22 \\
Recessive & & & & \\
W/W+W/D & $87(87)$ & $75(75)$ & Reference & - & 51 \\
D/D & $13(13)$ & $25(25)$ & $0.45(0.20-0.99)$ & 0.046 & 51 \\
Alleles & & & & \\
W & $106(53)$ & $87(44)$ & Reference & - & 40 \\
D & $94(47)$ & $113(56)$ & $0.68(0.45-1.03)$ & 0.072 & 40 \\
\hline
\end{tabular}

Table 2- Genotype and allele frequencies of DHFR 19-bp deletion polymorphism between patients with nonsyndromic cleft patients without $\mathrm{CP}$ and control subjects

\begin{tabular}{|c|c|c|c|c|c|}
\hline Genotypes & CL+CL/P n (\%) & Controls n (\%) & OR $(95 \% \mathrm{Cl})$ & P-value & Study Power \% \\
\hline \multicolumn{6}{|c|}{ DHFR, 19-bp deletion polymorphism } \\
\hline \multicolumn{6}{|l|}{ Codominant } \\
\hline W/W & $13(18.8)$ & $12(12)$ & Reference & - & 18 \\
\hline W/D & $48(69.6)$ & $63(63)$ & $0.70(0.30-1.68)$ & 0.428 & 11 \\
\hline $\mathrm{D} / \mathrm{D}$ & $8(11.6)$ & $25(25)$ & $0.30(0.01-0.90)$ & 0.032 & 50 \\
\hline \multicolumn{6}{|l|}{ Dominant } \\
\hline W/W & $13(18.8)$ & $12(12)$ & Reference & - & 18 \\
\hline$W / D+D / D$ & $56(81.2)$ & $88(88)$ & $0.59(0.23-1.49)$ & 0.271 & 18 \\
\hline \multicolumn{6}{|l|}{ Recessive } \\
\hline$W / W+W / D$ & $61(88.4)$ & $75(75)$ & Reference & - & 50 \\
\hline $\mathrm{D} / \mathrm{D}$ & $8(11.6)$ & $25(25)$ & $0.35(0.26-0.86)$ & 0.031 & 50 \\
\hline \multicolumn{6}{|l|}{ Alleles } \\
\hline W & $74(54)$ & $87(44)$ & Reference & - & 40 \\
\hline D & $64(46)$ & $113(56)$ & $0.66(0.41-1.08)$ & 0.067 & 40 \\
\hline
\end{tabular}

$(C L / P)=$ cleft lip with or without cleft palate

polymorphism between the $\mathrm{CL}+\mathrm{CL} / \mathrm{P}$ group and the control group. The association trend for the $\mathrm{CL}+\mathrm{CL} / \mathrm{P}$ group was almost the same as those for all cleft patients: the results demonstrated that DD genotype in the codominant model (D/D vs. W/W genotype; $\mathrm{OR}=0.30,95 \% \mathrm{CI}=0.01-0.90 ; \mathrm{P}=0.032$ ) as well as the DD genotype in the recessive model (D/D vs. W/W+W/D genotype; OR $=0.35,95 \%$ $\mathrm{CI}=0.26-0.86 ; \mathrm{P}=0.031$ ) were associated with a reduced risk of $C L+C L / P$.

\section{DISCUSSION}

In the current study, we investigated the impact of DHFR 19-bp deletion polymorphism on the risk of NS-CL/P. Our results demonstrated that the DHFR 19-bp homozygous D/D genotype (in both codominant and recessive models) was associated with a reduced risk of NS-CL/P. The results indicated that individuals carrying the DHFR 19-bp D/D genotype in the codominant and recessive models had, respectively, a 0.33 - and a 0.45 -fold reduced 
risk of developing NS-CL/P compared to those carrying the W/W genotype. We also stratified the cleft patients according to their etiology into $\mathrm{CP}$ and $\mathrm{CL}+\mathrm{CL} / \mathrm{P}$ patients, and evaluated the association of $D H F R$ 19-bp deletion polymorphism and the risk of $\mathrm{CL}+\mathrm{CL} / \mathrm{P}$ by comparing with the controls. The results demonstrated that the DD genotype in both codominant and recessive models was associated with a reduced risk of $\mathrm{CL}+\mathrm{CL} / \mathrm{P}$. Thus, our findings highlight the protective role of DHFR 19-bp deletion polymorphism against susceptibility to NS-CL/P in our population. Similarly, Parle-McDermott, et al. ${ }^{18}$ (2007) have shown a significantly lower risk of having a child with NTDs in women with the D/D or W/D genotypes than in women with the W/W genotype, suggesting that the 19-bp D allele may be a protective NTD genetic factor. However, other studies $^{13,17}$ have shown that the DHFR 19-bp D/D genotype vs. W/W genotype increased the risk of having a child with unilateral retinoblastoma or SB.

The polymorphic 19-bp deletion within intron-1 of DHFR appears to play important roles in the transcription of DHFR and the quantity of protein produced by translation. However, the precise consequence of the DHFR 19-bp deletion polymorphism has been controversial. Firstly, Johnson, et al. ${ }^{13}$ (2004) suggested the $D$ allele might decrease the DHFR expression, since the Sp1 transcription factor binding site is located within the deleted sequence. They suggested the homozygous $D / D$ genotype in mothers is related to an increased risk of preterm delivery ${ }^{12}$ or having a baby born with $\mathrm{SB}^{13}$. However, Parle-McDermott, et al. ${ }^{18}$ (2007) in a larger study have shown that the $D / D$ genotype is protective and decreases the risk of having a baby born with SB. Additionally, they ${ }^{18}$ reported that DHFR mRNA expression was $50 \%$ higher in lymphoblast cell lines with the D/D genotype than in cell lines with the W/W genotype. Moreover, Xu, et al. ${ }^{28}$ (2007) observed a dosedependent relation between DHFR expression and the $D / D$ genotype, proposing that subjects with the D/D genotype express 4.8-fold more DHFR mRNA levels compared to subjects carrying the 19-bp W/W genotype. Stanislawska-Sachadyn, et al.23 (2008) also reported that individuals with the D/D genotype have increased serum and red blood cell folate levels and lower homocysteine levels. These findings were confirmed by others ${ }^{10,25}$, who showed a significant decrease in plasma homocysteine concentration for the DHFR D/D genotype relative to the W/W genotype. This would affirm the possible maternal protective role of the 19-bp deletion allele in NS-CL/P by increasing the amount of DHFR available to reduce DHF to THF, and by augmenting bioavailability of folate cofactors required for a number of cellular reactions in pregnant women. However, any potential functional effect of the 19-bp deletion needs to be examined further in the context of the cell cycle and/or under low folate conditions. Martinelli, et al. ${ }^{20}$ (2014) also examined four SNPs of DHFR gene on cleft patients, and their study is different from ours in the way that we examined the 19-bp Ins/Del polymorphism of DHFR in cleft patients.

Multiple studies have demonstrated strong evidence for the contribution of Interferon regulatory factor 6 (IRF6) signalling pathway to the risk of nonsyndromic oral clefts across various ethnic groups. The IRF6 from chromosomal region 1q32.2 has previously been shown to account for the majority of patients with Van der Woude syndrome (VWS), the most common Mendelian deformity syndrome which includes oral clefts as a hallmark feature. Several genetic markers in IRF6 have provided evidence of linkage and linkage disequilibrium (LD) in studies of nonsyndromic oral clefts and have been associated with CL/P in many populations s, $^{54,30}$.

Variations in WNT (wingless-type MMTV integration site family) genes have also been associated with human nonsyndromic oral clefts. WNT signalling performs as an up-regulator of p63 and interferon regulatory factor 6 (IRF6), which regulates precise facial process fusion by controlling epithelial cell proliferation and differentiation. Variants within WNT genes were shown to contribute to cleft lip and palate, and mutations in WNT3 underlie autosomal-recessive tetra-amelia with cleft lip and palate. In family-based studies, a variety of WNT genes (WNT3A, WNT5A, WNT8A, and WNT11) have been shown to have an association with cleft lip/palate. Furthermore, studies in animal models have revealed the crucial role of WNTs family in craniofacial development. WNT3 and WNT9B are located in the cleft loci 1 (clf1) and could contribute to the clefting phenotype ${ }^{15}$. Targeted mutation in the mouse WNT9B gene resulted in an incomplete penetrance of CLP, suggesting the importance of WNTs in the pathogenesis of orofacial clefts ${ }^{3,16}$.

A number of other genes have also been implicated in NS-CL/P pathogenesis including transforming growth factor-alpha (TGFA), bone morphogenetic proteins (Bmp), fibroblast growth factors (Fgf), and members of the transforming growth factor $b$ (TGFB) superfamily. Mutations in TGFA, msh homeobox 1 (MSX1), fibroblast growth factor receptor 1 (FGFR1) and FGF8, and bone morphogenetic protein 4 (BMP4) have also been demonstrated to underlie the NS-CL/ $\mathrm{P}^{7}$. The presence of TGFA in the regulation of palate development and its high levels in medial edge epithelia (MEE) of palatal shelves have been demonstrated ${ }^{29}$. Bmp2 and Bmp4 are expressed more specifically within the epithelia and mesenchyme of the palatal shelves. The 
Msx1 homeobox gene, which is also expressed in the facial primordia, is needed for expression of Bmp2 and Bmp4 in the palatal mesenchyme. In addition, epidermal growth factor (EGF) stimulates glycosaminoglycan production within the palatal shelves ${ }^{7,29}$.

Orofacial development is a quite harmonized process of cell proliferation, differentiation, migration, and apoptosis. The quick growth and the consecutive fusion of maxillary processes and palatal shelves during early embryogenesis are crucial stages in orofacial development, both requiring an effective methyl synthesis and availability ${ }^{21}$. DHFR is also needed for the intracellular conversion of synthetic folic acid, consumed in supplements and fortified foods, into the THF forms that can contribute to folate/homocysteine metabolism. Defective DHFR activity has been associated with a rapid depletion of THF pool within the cell affecting the level of folate coenzymes and hence purine and pyrimidine synthesis, and consequent termination of de-novo DNA synthesis and histone methylation, that are all essential for cell proliferation and regulation of gene expression during embryonic development ${ }^{10}$. The use of folic acid supplementation during pregnancy in protection against congenital malformations such as OFCs ${ }^{2}$, NTD ${ }^{4}$, and $\mathrm{SB}^{27}$ has been supported by several studies. These studies support the protective role of folic acid intake during the pre-, peri-, and postconceptional periods on the risk of $\mathrm{OFCs}^{8}$, suggesting that the occurrence of OFCs can be reduced with prophylactic use of folate by women in the periconceptional period. Two hypotheses may explain the harmful effects of low folate levels during pregnancy.

One of the limitations of our study is the relatively small sample size. Therefore, the results should be interpreted with caution. Furthermore, our study deviated somehow from HWE (Hardy Weinberg Equilibrium). There is no clear explanation for the deviation from HWE in our population. However, the small sample size, consanguineous marriages, or genetic drift could be possible reasons in this population.

\section{CONCLUSIONS}

Our data suggests that DHFR 19-bp D/D genotype is associated with a reduced risk of NS$\mathrm{CL} / \mathrm{P}$ in both the codominant and recessive models. This finding highlights the protective role of DHFR 19-bp deletion polymorphism against susceptibility to NS-CL/P in an Iranian population. Future research with larger samples from different ethnicities is required to validate our findings.

\section{ACKNOWLEDGEMENT}

This paper was funded from Doctorate thesis grant of FR from the deputy for Research, Zahedan University of Medical Sciences.

\section{DISCLOSURE OF CONFLICTING INTERESTS}

The authors declare that there is no conflict of interest to disclose.

\section{REFERENCES}

1- Badovinac RL, Werler MM, Williams PL, Kelsey KT, Hayes C. Folic acid-containing supplement consumption during pregnancy and risk for oral clefts: a meta-analysis. Birth Defects Res A Clin Mol Teratol. 2007;79:8-15.

2- Beaty TH, Ruczinski I, Murray JC, Marazita ML, Munger RG, Hetmanski JB, et al. Evidence for gene-environment interaction in a genome wide study of nonsyndromic cleft palate. Genet Epidemiol. 2011;35:469-78.

3- Chiquet BT, Blanton SH, Burt A, Ma D, Stal S, Mulliken JB, et al. Variation in WNT genes is associated with non-syndromic cleft lip with or without cleft palate. Hum Mol Genet. 2008;17:2212-8. 4- Czeizel AE. Periconceptional folic acid and multivitamin supplementation for the prevention of neural tube defects and other congenital abnormalities. Birth Defects Res A Clin Mol Teratol. 2009;85:260-8.

5- Desmyter L, Ghassibe M, Revencu N, Boute O, Lees M, Francois $G$, et al. IRF6 screening of syndromic and a priori non-syndromic cleft lip and palate patients: identification of a new type of minor VWS sign. Mol Syndromol. 2010;1:67-74.

6- Desrosiers TA, Lawson CC, Meyer RE, Richardson DB, Daniels $\mathrm{J}$, Waters MA, et al. Maternal occupational exposure to organic solvents during early pregnancy and risks of neural tube defects and orofacial clefts. Occup Environ Med. 2012;69:493-9.

7- Dixon MJ, Marazita ML, Beaty TH, Murray JC. Cleft lip and palate: understanding genetic and environmental influences. Nat Rev Genet. 2011;12:167-78.

8- Estandia-Ortega B, Velázquez-Aragón JA, Alcántara-Ortigoza MA, Reyna-Fabian ME, Villagómez-Martínez S, González-Del Angel A. 5,10-Methylenetetrahydrofolate reductase single nucleotide polymorphisms and gene-environment interaction analysis in non-syndromic cleft lip/palate. Eur J Oral Sci. 2014;122:109-13. 9- Fisk Green R, Byrne J, Crider KS, Gallagher M, Koontz D, Berry $\mathrm{RJ}$. Folate-related gene variants in Irish families affected by neural tube defects. Front Genet. 2013;4:223.

10- Gellekink H, Blom HJ, van der Linden IJ, den Heijer M. Molecular genetic analysis of the human dihydrofolate reductase gene: relation with plasma total homocysteine, serum and red blood cell folate levels. Eur J Hum Genet. 2007;15:103-9.

11- Gemmati D, De Mattei M, Catozzi L, Della Porta M, Serino ML, Ambrosio C, et al. DHFR 19-bp insertion/deletion polymorphism and MTHFR C677T in adult acute lymphoblastic leukaemia: is the risk reduction due to intracellular folate unbalancing? Am J Hematol. 2009;84:526-9.

12- Johnson WG, Scholl TO, Spychala JR, Buyske S, Stenroos ES, Chen X. Common dihydrofolate reductase 19-base pair deletion allele: a novel risk factor for preterm delivery. Am J Clin Nutr. 2005;81:664-8.

13- Johnson WG, Stenroos ES, Spychala JR, Chatkupt S, Ming SX, Buyske S. New 19 bp deletion polymorphism in intron-1 of dihydrofolate reductase (DHFR): a risk factor for spina bifida acting in mothers during pregnancy? Am J Med Genet A. 2004;124A:339-45. 
14- Martinelli M, Girardi A, Cura F, Carinci F, Morselli PG, Scapoli L. Evidence of the involvement of the DHFR gene in nonsyndromic cleft lip with or without cleft palate. Eur J Med Genet. 2014;57:1-4. 15- Menezes R, Letra A, Kim AH, Küchler EC, Day A, Tannure $\mathrm{PN}$, et al. Studies with Wnt genes and nonsyndromic cleft lip and palate. Birth Defects Res A Clin Mol Teratol. 2010;88:995-1000. 16- Mostowska A, Hozyasz KK, Biedziak B, Wojcicki P, Lianeri M, Jagodzinski PP. Genotype and haplotype analysis of WNT genes in non-syndromic cleft lip with or without cleft palate. Eur J Oral Sci. 2012;120:1-8.

17- Orjuela MA, Cabrera-Muñoz L, Paul L, Ramirez-Ortiz MA, Liu X, Chen $\mathrm{J}$, et al. Risk of retinoblastoma is associated with a materna polymorphism in dihydrofolatereductase (DHFR) and prenatal folic acid intake. Cancer. 2012;118:5912-9.

18- Parle-McDermott A, Pangilinan F, Mills JL, Kirke PN, Gibney ER, Troendle J, et al. The 19-bp deletion polymorphism in intron-1 of dihydrofolate reductase (DHFR) may decrease rather than increase risk for spina bifida in the Irish population. Am J Med Genet A. 2007; 143A: 1174-80.

19- Rafighdoost $H$, Hashemi M, Narouei A, Eskanadri-Nasab E, Dashti-Khadivaki G, Taheri M. Association between $\mathrm{CDH} 1$ and MSX1 gene polymorphisms and the risk of nonsyndromic cleft lip and/or cleft palate in a southeast Iranian population. Cleft Palate Craniofac J. 2013;50:e98-e104.

20- Riley BM, Mansilla MA, Ma J, Daack-Hirsch S, Maher BS, Raffensperger LM, et al. Impaired FGF signaling contributes to cleft lip and palate. Proc Natl Acad Sci U S A. 2007;104:4512-7. 21- Riley BM, Schultz RE, Cooper ME, Goldstein-McHenry T, DaackHirsch S, Lee KT, et al. A genome-wide linkage scan for cleft lip and cleft palate identifies a novel locus on 8p11-23. Am J Med Genet A. 2007;143A:846-52.

22- Smithells RW, Sheppard S, Schorah CJ, Seller MJ, Nevin NC, Harris R, et al. Possible prevention of neural-tube defects by periconceptional vitamin supplementation. Lancet. 1980;1:33940.
23- Stanislawska-Sachadyn A, Brown KS, Mitchell LE, Woodside JV, Young IS, Scott JM, et al. An insertion/deletion polymorphism of the dihydrofolate reductase (DHFR) gene is associated with serum and red blood cell folate concentrations in women. Hum Genet. 2008;123:289-95.

24- Tang W, Du X, Feng F, Long J, Lin Y, Li P, et al. Association analysis between the IRF6 G820A polymorphism and nonsyndromic cleft lip and/or cleft palate in a Chinese population. Cleft Palate Craniofac J. 2009;46:89-92.

25- Van der Linden IJ, Nguyen U, Heil SG, Franke B, Vloet S, Gellekink $H$, et al. Variation and expression of dihydrofolate reductase (DHFR) in relation to spina bifida. Mol Genet Metab. 2007;91:98-103.

26- Webster WS, Howe AM, Abela D, Oakes DJ. The relationship between cleft lip, maxillary hypoplasia, hypoxia and phenytoin. Curr Pharm Des. 2006;12:1431-48.

27- Wilson RD, Johnson JA, Wyatt P, Allen V, Gagnon A, Langlois $S$, et al. Pre-conceptional vitamin/folic acid supplementation 2007: the use of folic acid in combination with a multivitamin supplement for the prevention of neural tube defects and other congenital anomalies. J Obstet Gynaecol Can. 2007;29:1003-26. 28- Xu X, Gammon MD, Wetmur JG, Rao M, Gaudet MM, Teitelbaum $\mathrm{SL}$, et al. A functional 19-base pair deletion polymorphism of dihydrofolate reductase (DHFR) and risk of breast cancer in multivitamin users. Am J Clin Nutr. 2007;85:1098-102.

29- Yuan Q, Blanton SH, Hecht JT. Genetic causes of nonsyndromic cleft lip with or without cleft palate. Adv Otorhinolaryngol. 2011;70:107-13.

30- Zucchero TM, Cooper ME, Maher BS, Daack-Hirsch S, Nepomuceno B, Ribeiro $L$, et al. Interferon regulatory factor 6 (IRF6) gene variants and the risk of isolated cleft lip or palate. $\mathrm{N}$ Engl J Med. 2004;351:769-80. 